\title{
THE ROLE OF COMMUNITY SIZE IN THE EMERGENCE OF LINGUISTIC STRUCTURE
}

\author{
LIMOR RAVIV $^{* 1}$, ANTJE MEYER ${ }^{, 2}$, and SHIRI LEV-ARI ${ }^{1,3}$ \\ *Corresponding Author: limor.raviv@mpi.nl \\ ${ }^{1}$ Max Planck Institute for Psycholinguistics, Nijmegen, The Netherlands \\ ${ }^{2}$ Radboud University, Nijmegen, The Netherlands \\ ${ }^{3}$ Royal Holloway University of London, Egham, UK
}

\section{Community Structure Affects Linguistic Structure}

Over the last decade, several diachronic and typological analyses showed that the structure of languages spoken in exoteric societies is different from the structure of languages spoken in esoteric societies (e.g., Lupyan \& Dale, 2010; Meir, Israel, Sandler, Padden \& Aronoff, 2012; Nettle, 2012; Trudgill, 2009; Wray \& Grace, 2007). These studies propose that different linguistic structures may emerge in different communities depending on their social properties. In particular, it has been argued that increased population size, sparser community structure and higher proportion of adult L2 learners in the community lead to morphological simplification. However, these three community properties are confounded in the real world, making it hard to evaluate their role separately. Additionally, the role of community size has not been experimentally tested.

\section{The Current Studies}

In the current studies, we focus on one property of community structure, namely, population size, and experimentally test the effect of different community sizes on the emergence of structure using a novel group communication game.

In Experiment 1 we tested six small communities of four participants and six larger communities of eight participants. Communities interacted in alternating dyads for seven rounds using an artificial language that was created by the participants on-the-go to refer to a meaning space that expanded with time. This was followed by a test round. At this point in time, all participants had the same amount of interaction and experience overall, but members of larger communities had less shared history with each other (i.e., each pair in the community has interacted fewer times). To equate the degree of shared history, larger communities were given seven additional communication rounds and an additional test round. In Experiment 2 we tested six more small communities 
that played as long as the larger communities in Experiment 1, and compared their performance to the larger communities across all 16 rounds to examine whether the differences found in Experiment 1 hold at a later point in time.

\subsection{Results}

We found that both small and larger communities developed compositional structure over time (measured as the average correlation between labels' string distances and meaning distances in the community, following Kirby, Tamariz, Cornish \& Smith, 2015). Crucially, larger communities developed linguistic structure faster and more consistently than small groups. While there was no difference between the structure created by small and larger communities after eight rounds (seven communication rounds + test round), by the $16^{\text {th }}$ round, larger communities had more compositional structure than small communities (Figure 1). In addition, small and larger communities showed similar trends of stabilization and conventionalization by the $16^{\text {th }}$ round. Communicative success was not influenced by community size at any point in time. Finally, small communities showed significantly more variance than larger communities on all measures.

Together, and in line with previous typological studies (e.g. Lupyan \& Dale, 2010), our findings demonstrate experimentally that population size can affect the formation of linguistic structure (as well as other linguistic properties), with larger communities developing structured languages faster and more consistently over time. These results highlight the role of the social environment in explaining patterns of linguistic diversity and trajectories of language change.

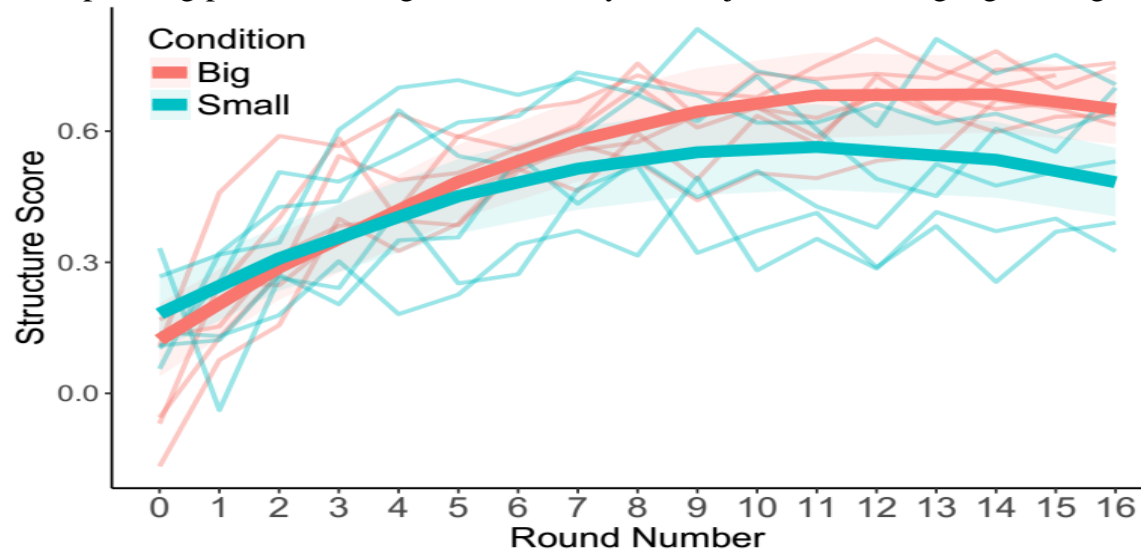

Figure 1. Linguistic structure by round number and community size. Only communities that played for 16 rounds are plotted (from both Experiment $1 \& 2$ ). 


\section{Acknowledgments}

We wish to thank Caitlin Decuyper for programming the experiment, and Gary Lupyan, Mark Atkinson, Sean Roberts and Kevin Stadler for discussions and helpful input.

\section{References}

Lupyan, G., \& Dale, R. (2010). Language structure is partly determined by social structure. PloS one, 5(1), e8559.

Meir, I., Israel, A., Sandler, W., Padden, C. A., \& Aronoff, M. (2012). The influence of community on language structure: evidence from two young sign languages. Linguistic Variation, 12(2), 247-291.

Wray, A., \& Grace, G. W. (2007). The consequences of talking to strangers: Evolutionary corollaries of socio-cultural influences on linguistic form. Lingua, 117(3), 543-578

Trudgill, P. (2009). Sociolinguistic typology and complexification. In G. Sampson, D. Gil, and P. Trudgill (eds.), Language Complexity as an Evolving Variable. Oxford: Oxford University Press.

Nettle, D. (2012). Social scale and structural complexity in human languages. Phil. Trans. R. Soc. B, 367(1597), 1829-1836.

Kirby, S., Tamariz, M., Cornish, H., \& Smith, K. (2015). Compression and communication in the cultural evolution of linguistic structure. Cognition, 141, 87-102. 